\title{
PENGALAMAN ORANG TUA MENERIMA PERILAKU CARING PERAWAT DALAM MEMFASILITASI BONDING ATTACHMENT BAYI PREMATUR
}

\author{
Laviana Nita Ludyanti $^{*}$, Yeni Rustina ${ }^{2}$, Yati Afiyanti ${ }^{2}$ \\ 1. Program Studi Magister, Fakultas Ilmu Keperawatan, Universitas Indonesia, Depok 16424, Indonesia \\ 2. Fakultas Ilmu Keperawatan, Universitas Indonesia, Depok 16424, Indonesia \\ *E-mail: laviananl@gmail.com
}

\begin{abstract}
Abstrak
Perpisahan dengan orang tua akibat perawatan pada bayi prematur berpengaruh terhadap proses bonding attachment. Penelitian kualitatif dengan pendekatan fenomenologi deskriptif pada tujuh partisipan ini menggunakan teknik purpossives sampling yang bertujuan untuk mengeksplorasi secara mendalam pengalaman orang tua menerima perilaku caring perawat dalam memfasilitasi bonding attachment bayi prematur di Ruang NICU. Pengumpulan data dilakukan dengan wawancara mendalam dan dianalisis dengan metode Colaizzi. Hasil analisis data mendapatkan tujuh tema, yaitu proses peningkatan pengetahuan, mampu melakukan perawatan terhadap bayinya, respons ibu terhadap tindakan perawatan yang diberikan, termotivasi dalam melakukan perawatan bayi prematur, terpenuhinya kebutuhan bayi selama dilakukan perawatan, keterlibatan dalam asuhan keperawatan, dan kepuasan terhadap perawatan. Penelitian ini diharapkan dapat meningkatkan asuhan keperawatan dan bonding attachment pada bayi prematur.
\end{abstract}

Kata kunci: bayi prematur, pengalaman ibu, perilaku caring perawat, perawatan intensif neonatus

\begin{abstract}
Experience Caring Parents Receive The Behavior of Nurses in Premature Infants Facilitate Bonding Attachment. Separation between parents and premature babies in intensive care unit affects in bonding attachment process. This study was a qualitative research design with descriptive phenomenology approach took 7 participants used Purpossive Sampling Technique. This study aims to explore mother's experience received nursing caring in facilitated bonding attachment of premature babies. Data were collected with indepht interview and analized with Colaizzi method. The results of data analysis got seven themes: knowledge improving process; capable to cared their babies; mother's respons with nursing care; was motivated to cared their premature babies, the premature babies needed was fullfiled well; participated in nursing care; and nursing care satisfaction. The result is expectedto be inputin improvingnursing care and bonding attachment in premature babies.
\end{abstract}

Keywords: premature babies, mother's experiences, nursing caring, neonatus intensive care

\section{Pendahuluan}

Usia gestasi dan berat badan lahir merupakan hal yang sangat penting dalam memprediksi kesehatan dan kematian bayi. Bayi dengan usia gestasi kurang dari 32 minggu (prematur) berisiko tinggi mengalami kematian atau kecacatan baik dalam jangka panjang maupun pendek (Cloherty, Eichen-wald, \& Stark, 2008). Masalah kesehatan yang banyak muncul pada bayi prematur diantaranya adalah gangguan pada sistem respirasi (Juretschke, 2007; Lopez, Anderson, \& Fentchinger, 2012),

kardiovaskuler, penyakit infeksi, pertumbuhan, dan nutrisi (Juretschke, 2007), jaundice serta lama perawatan di rumah sakit (Lopez, Anderson, \& Fentchinger, 2012). Menurut Potts dan Mandleco (2012), komplikasi bayi prematur semakin meningkat seperti Intraventricular Haemorrhage (IVH) (15-20\%) pada bayi dengan usia gestasi kurang dari 32 minggu, kematian akibat Necrotizing Enterocolitis (NEC) (28\%) dan Retinopathy 
of Prematurity (ROP) (65\%) pada bayi yang lahir kurang dari 1250 gram.

Peningkatan komplikasi pada bayi prematur menyebabkan perlunya perawatan yang maksimal dan intensif (Montanholli, Merighi, \& Pinto de Jesus, 2011) di Neonatal Intensive Care Unit (NICU). Bayi akan mendapatkan berbagai macam tindakan dan prosedur selama menjalani perawatan di ruang intensif. Selain itu, lingkungan eksternal termasuk kondisi perpisahan dengan orang tua terutama ibu dan sibling (Goldson, 1999; Boxwell, 2007), memberikan dampak secara emosional dan psikologis pada bayi dan orang tua yang mungkin saja menimbulkan kekhawatiran terhadap kemampuan orang tua dalam merawat bayi dan dapat memunculkan juga depresi maternal (Davis, Edwards, Mohay, \& Wollin, 2003). Hal ini tentunya akan menambah faktor risiko yang dapat memperburuk interaksi antara ibu dengan bayi (Guillaume, et al., 2013).

Kualitas bonding attachment yang dilakukan lebih awal akan memengaruhi perkembangan fisik dan emosional bayi di masa yang akan datang ketika mereka dewasa dan memiliki anak. Interaksi ini akan menjadikan orang tua dan anak lebih mengenal dan lebih sensitif terhadap perilaku satu sama lain (Willinger, Diendorfer-Radner, Wilnauer, Jorgl, \& Hager, 2005; Chapman \& Durham, 2010) yang merefleksikan tingkat kepercayaan diri anak, meningkatkan kemampuan berinteraksi sosial, dan kemampuan koping dalam menghadapi stress (Willinger, Diendorfer-Radner, Wilnauer, Jorgl \& Hager, 2005). Berdasarkan hal tersebut, bonding attachment merupakan hal yang sangat penting dan perlu difasilitasi oleh perawat di ruang intensif secepat mungkin setelah bayi lahir (White, Duncan, \& Baumle, 2011).

\section{Metode}

Penelitian ini menggunakan metode penelitian kualitatif dengan pendekatan studi fenomenologi deskriptif. Partisipan dalam penelitian ini adalah orang tua dengan bayi prematur yang bayinya dirawat di ruang NICU sebanyak tujuh partisipan. Partisipan diambil dengan menggunakan teknik purposive sampling. Adapun kriteria inklusi yang ditetapkan peneliti adalah orang tua yang memiliki bayi prematur dan memiliki pengalaman memperoleh perilaku caring dari perawat, orang tua adalah ibu dengan bayi prematur yang dirawat di ruang NICU dan yang akan menjalani perawatan di rumah serta orang tua mampu menceritakan dengan baik pengalamannya dan bersedia menjadi partisipan.

Pedoman penentuan jumlah sampel berdasarkan adanya saturasi data. Penelitian ini dilakukan di ruang NICU Rumah Sakit Umum Daerah (RSUD) dr. Iskak Tulungagung dan dilakukan bulan AprilJuni 2014. Pengumpulan data dilakukan melalui wawancara mendalam. Analisis data menggunakan Metode Colaizzi. Peneliti mengolah dan mempersiapkan data, membaca keseluruhan data, melakukan coding data, mendeskripsikan data, menyajikan data dalam bentuk narasi, dan menginterpretasi data.

Penelitian ini telah melalui kaji etik Komite Etik Riset Fakultas Ilmu Keperawatan Universitas Indonesia.

\section{Hasil}

Pengalaman orang tua (ibu) menerima perilaku caring perawat dalam memfasilitasi bonding attachment pada bayi prematur memiliki pandangan yang berbeda dari setiap partisipan. Tema pertama yang teridentifikasi adalah proses peningkatan pengetahuan yang tergambar dalam kalimat berikut.

"Tapi ya paling tidak sedikit-sedikit saya sudah tau. Ganti-ganti pampers gitu."(P3).

"Ya, dibilangi gitu, kalau sudah ada perubahan, sudah bagus gitu, minumnya juga sudah bagus. Saya jadinya ngerti gitu...."(P4).

"Enggak terlalu tau, Bu. Makanya, kan, enggak ngerti, kan, Mbak. Soalnya saya enggak dibilangi. Saya juga enggak tahu, kok, Mbak bagaimana caranya merawat bayi."(P6). 
Tema berikutnya adalah mampu melakukan perawatan terhadap bayinya setelah diajari dan diberikan informasi oleh perawat. Pernyataan ibu yang mendukung tema tersebut dapat dilihat dalam kutipan berikut ini.

"Kalau memang pengen tahu, waktu susternya apa itu...mandiin atau ganti popok gitu, ya melihat sekali gitu, ya sudah bias."(P1).

"Iya insyaallah bisa, yakin bisalah, Bu..."(P4).

"Terus sekarang mengerjakan sendiri semakin berani. “(P5).

Ibu menyatakan senang, tenang, dan bersyukur terhadap perawatan yang telah diberikan. Tema ketiga ini didukung pernyataan ibu sebagai berikut.

"Ya anaknya sudah dalam keadaan bersih. Itu yang saya suka."(P4).

"Iya saya bersyukur banget. Sama MbakMbaknya (perawat) juga dibilangi gitu...."(Pl).

"Tapi sekarang alhamdulilah sudah ada perubahannya”(P4).

"Tapi kalau sekarang sudah tidak berpikir macam-macam”(Pl).

"Ya kalau sudah dikasih tahu perawatnya gitu, ya sudah agak tenang. ”(P3).

Ibu menyatakan termotivasi dengan adanya perilaku caring perawat. Hal ini nampak pada usaha ibu untuk mendapatkan informasi yang lebih banyak terhadap kondisi dan cara merawat bayinya. Tema keempat ini ditunjukkan oleh pernyataan ibu sebagai berikut.

"Iya.... Nanti setidak-tidaknya bertanyalah, pokoknya berusaha”(P4).
"Iya, jadi semangat melihat perkembangan adiknya." (P2).

Perawat melakukan pemenuhan kebutuhan nutrisi dengan memberikan susu, membersihkan bayi saat buang air kecil (BAK) maupun buang air besar (BAB), serta memfasilitasi ibu untuk dekat dengan bayinya. Tema kelima ini digambarkan dalam pernyataan berikut.

"Ya, perawatnya semua yang melakukan, ngasih minum, ganti pampers, ganti baju. Semua ya, sudah dipakaikan ke bayinya oleh perawatnya."(P7).

Terdapat lima partisipan yang mengatakan perawat mengikutsertakan ibu dalam perawatan bayinya. Perawat memberi kesempatan kepada ibu untuk melihat dan belajar dalam memberikan perawatan terhadap bayinya. Tema keenam ini dapat digambarkan dalam pernyataan ibu sebagai berikut.

"Pekerjaan gitu saya dilibatkan...ya seneng...sambil belajar..."(P1).

“...Ya ikut...ikut melihat gitu biar tahu, sambil belajar...”(P3).

“...ya kalau pas pasang bedong, memakaikan pampers gitu saya ikut melihat, boleh ikut."(P7).

Kepuasan pasien juga diungkapkan oleh ibu melalui pernyataan-pernyataan sebagai berikut. Ibu menyatakan bahwa perawat telah melakukan penanganan dan perawatan yang terampil. Pernyataan yang mendukung tema terakhir ini ada di bawah ini.

"Tapi kalau di sini langsung, cakcek (gesit, segera ditangani) gitu lho, pokoknya cepat terus alat-alat juga komplit. Itu mudahnya ya di situ itu” (P1).

"Kan sudah dipercaya anaknya dirawat disini, percaya supaya anaknya cepat sembuh."(P4). 
"Ya obat-obatnya untuk bayi-bayi segitu, kan, ya bagus. Buktinya mereka yang dirawat di sini, ya bisa sehat-sehat."(P7).

\section{Pembahasan}

Teori caring Watson dalam salah satu faktor karatifnya menyatakan bahwa perawat memiliki kemampuan untuk meningkatkan sistem pembelajaran interpersonal. Perawat hendaknya melakukan proses pembelajaran yang menarik dan sungguh-sungguh termasuk diantaranya adalah memberikan informasi pada pasien dan keluarganya, memberikan pengertian tentang kesehatan, serta berbagi pengalaman dengan pasien dan keluarga (Alligood, 2010). Pemberian informasi yang mudah dimengerti oleh keluarga menunjukkan sensitivitas dan penghargaan terhadap orang tua serta dapat mengurangi adanya kebingungan pada saat merencanakan asuhan keperawatan dan mengetahui kondisi anaknya (Gillespie, et al., 2012).

Keluarga maupun tenaga kesehatan, yaitu perawat merupakan faktor yang dapat memengaruhi proses belajar tersebut. Kemampuan perawat dalam memberikan informasi kepada ibu serta karakteristik ibu yang berbeda mempunyai pengaruh yang besar terhadap proses peningkatan pengetahuan terutama dalam menjalin bonding attachment dan memberikan perawatan kepada bayi prematur. Partisipan mengungkapkan bahwa perawat memberikan informasi tentang perkembangan bayinya, cara perawatan, pemberian nutrisi, serta kedekatan orang tua dan bayi. Karakteristik partisipan dengan tingkat pendidikan yang berbeda memengaruhi proses peningkatan pengetahuan. Demikian pula dengan pengalaman sebelumnya yang dimiliki oleh partisipan.

Penelitian yang seiring dengan penelitian ini adalah penelitian Wilkin dan Slevin (2004) yang mengeksplorasi makna caring di ruang ICU (Intensive Care Unit). Hasil penelitian mengidentifikasi adanya beberapa tema, yaitu perasaan perawat, pengetahuan perawat, dan keterampilan perawat. Pengetahuan perawat meliputi kompetensi teknik, pengalaman pengetahuan dan profesionalitas, memahami pasien, merawat orang lain dengan tepat, prioritas perawatan, teknologi, dan situasi kritis. Selain itu, keterampilan perawat meliputi interaksi perawat dan pasien, advokat, fisik, dorongan, dan hambatan dalam perawatan.

Orang tua dengan bayi prematur tentunya lebih banyak membutuhkan hal-hal yang harus dipelajari dan disiapkan dalam perawatan bayinya. Peran perawat adalah memampukan orang tua terutama ibu. Hal ini sesuai dengan komponen caring yang diungkapkan oleh Arnold dan Boggs (2003), yaitu empowerment (pemberdayaan). Pemberdayaan bertujuan untuk mengurangi kegagalan ibu dalam merawat bayinya di rumah setelah bayi dipulangkan. Teori caring Swanson (1995) dalam enabling human being menyatakan bahwa perawat memfasilitasi kemampuan orang lain untuk melakukan perawatan terhadap dirinya sendiri maupun anggota keluarganya.

Berdasarkan konsep Becoming a mother, pada tahap pengenalan, proses belajar dan keberadaan secara fisik, ibu mulai mengenal bayinya dan mulai belajar berbagai hal tentang bayi dan perawatannya (Hushmilo, 2013). Hal ini dapat digambarkan dalam hasil penelitian bahwa orang tua (ibu) berusaha untuk mengerti dan memahami kondisi bayinya serta belajar untuk merawat bayi. Orang tua (ibu) mempunyai keinginan untuk belajar agar dapat melakukan perawatan secara mandiri dan bayinya mencapai derajat kesehatan yang lebih optimal. Perawat memfasilitasi kebutuhan orang tua tersebut dengan memberi kesempatan pada ibu untuk belajar memahami bayinya dan melakukan perawatan.

Hasil penelitian ini menggambarkan perawat telah melakukan perilaku caring dalam meningkatkan kemampuan orang tua untuk bonding attachment maupun perawatan bayi prematur yang diungkapkan partisipan dalam tema mampu melakukan perawatan terhadap bayinya. Perawat mengajari orang tua (ibu) berbagai hal, seperti mengajari cara menyusui yang benar, mengajari cara menjalin kedekatan dengan bayi, mengajari perawatan metode kanguru, mengajari perawatan bayi, serta mengajari untuk mengetahui adanya tanda-tanda kegawatan terhadap bayi sehingga 
orang tua merasa mampu melakukan perawatan terhadap bayinya yang prematur.

Masa transisi, kondisi bayi yang prematur, dan lingkungan perawatan akan meningkatkan kekhawatiran, kecemasan, dan ketakutan terhadap orang tua. Hal ini perlu menjadi perhatian bagi seorang perawat dalam melakukan asuhan keperawatan terhadap pasien. Kondisi bayi prematur memotivasi perawat maupun orang tua untuk melakukan perawatan yang optimal. Perawat mengajarkan orang tua cara merawat bayi prematur yang meliputi aspek pemenuhan kebutuhan dasar, seperti pemberian nutrisi dan menjaga kebersihan. Selain itu, perawat juga memotivasi orang tua (ibu) untuk selalu menjalin kedekatan dengan bayinya, sabar dan teliti dalam melakukan merawat bayi agar bayi cepat sehat.

Pada dimensi caring Swanson tentang maintaining belief in, proses caring memfasilitasi pasien atau orang tua untuk meningkatkan kepercayaan diri sesuai dengan kemampuannya untuk mengetahui arti hidupnya, lebih optimis dan teguh pendirian (Swanson, 1995). Caring yang dilakukan oleh perawat menjadikan ibu lebih termotivasi untuk belajar dan melakukan perawatan terhadap bayinya yang prematur.

Perilaku caring yang paling pokok dalam pemberian asuhan keperawatan adalah membantu memenuhi kebutuhan pasien dan sensitif pada diri sendiri dan orang lain (Gillespie, et al., 2012). Hal ini juga diungkapkan oleh Watson dalam Aligood, 2010, melalui sepuluh karatif caring yang salah satunya adalah kepuasan dalam memenuhi kebutuhan dasar manusia. Perawat selalu membantu memenuhi kebutuhan dasar pasien. baik secara fisik maupun psikologis untuk memberikan kenyamanan kepada pasien. Pada penelitian ini, ibu menyatakan bahwa bayinya yang menjalani perawatan selalu dalam keadaan bersih dan rapi saat diberikan kepada ibunya. Pada waktunya minum susu, perawat juga memberikan susu kepada bayi, serta memberi kesempatan kepada ibu untuk menyusui. Perawat juga memfasilitasi kedekatan ibu dengan bayinya. Hal ini menunjukkan bahwa perawat memenuhi kebutuhan bayi, baik secara fisik maupun psiko- logis dengan baik. Tindakan perawat tersebut menggambarkan perilaku caring perawat dalam melakukan pemenuhan kebutuhan dasar.

Keluarga merupakan bagian terpenting dalam perawatan pasien. Anggota keluarga diharapkan ikut bertanggung jawab dalam memenuhi kebutuhan pelayanan yang kompleks (Lewis, Gundwarden, \& Saadawi, 2005). Watson juga menjelaskan bahwa melibatkan anggota keluarga dalam memotivasi pasien dan mengambil keputusan adalah suatu hal yang penting dalam perawatan (Watson \& Foster, 2003).

Keterlibatan ibu dalam perawatan juga akan meningkatkan kemampuan ibu dalam belajar melakukan perawatan kepada bayi prematur. Hasil penelitian menyatakan bahwa tidak semua perawat di ruang perawatan intensif melibatkan ibu dalam perawatan bayinya. Ibu menyatakan bahwa perawat melakukan perawatan bayi sendiri dan hanya melibatkan ibu saat pemberian nutrisi saja. Ibu lainnya menyatakan bahwa perawat memfasilitasi keterlibatan ibu dalam perawatan. Hal ini berarti bahwa perawat belum benarbenar melibatkan ibu dalam perawatan bayi prematur.

Kehadiran orang tua (ibu) di dekat bayinya memberikan efek yang positif terhadap perkembangan bayi prematur yang dirawat di ruang NICU. Perawat selalu berusaha meminta ibu untuk datang ke ruang perawatan pada setiap jam menyusui, meskipun bayi yang sedang dirawat belum bisa disusui secara langsung dengan tujuan agar ibu dapat lebih dekat dan menunggui bayinya. Kedekatan antara orang tua dan anak dapat terjalin melalui sentuhan, eksplorasi perasaan, berbicara, dan menggunakan kontak mata (White, Duncan, \& Baumle, 2011). Bonding akan semakin meningkat pada saat orang tua melakukan sentuhan dan interaksi dengan bayinya (Bowden, Dickey, \& Greenberg, 1998). Jadi ketika orang tua (ibu) merasa takut melakukan kontak fisik dan komunikasi verbal dengan bayinya, kedekatan antara orang tua dan bayi juga akan mengalami hambatan. Hal ini tentunya juga akan berpengaruh terhadap perkembangan bayi di masa yang akan datang karena bonding attachment tidak dapat 
terjalin dengan baik. Oleh sebab itu, keterlibatan ibu dalam perawatan merupakan hal yang sangat penting dalam menjalin bonding attachment.

Perawat NICU sebaiknya mendampingi orang tua saat bersama dengan bayinya, memberi kesempatan untuk menyentuh, memegang, dan mendampingi bayinya lebih dekat. Hal ini merupakan tindakan yang dapat membantu orang tua untuk menguatkan ikatan emosional dengan bayinya (Merighi, Pinto de Jesus, Santin, \& Oliveira, 2011). Hasil penelitian ini juga menyatakan bahwa perawat memberi kesempatan kepada ibu untuk menyentuh, memegang, berada di dekat bayi, mengajak berbicara bahkan menyanyi untuk bayinya sebagai bentuk keterlibatan ibu dalam perawatan.

Kepuasan orang tua merupakan indikator penting dalam perawatan di NICU dalam mencapai derajat kesembuhan dan kesehatan bayi (Hawes, 2009). Menurut Cunningham, et al., (2005), harapan pasien terhadap perawatan meliputi adanya staff yang kompeten, perawatan atau penanganan yang cepat, perawatan yang menyenangkan, perawatan yang efektif, lama perawatan yang lebih cepat, dan kesembuhan pasien lebih cepat.

Berdasarkan studi kualitatif yang dilakukan oleh Harbaugh, Tomlinson, dan Kirschbaum (2004), harapan orang tua terhadap perawat dalam memberikan asuhan keperawatan adalah menunjukkan kualitas keterlibatan, pengawasan dan perlindungan. Perilaku caring yang dilakukan perawat termasuk memberikan informasi pada orang tua dan keluarga, menghargai keunikan dari anak, dan memberikan perawatan yang kompeten.

Keberhasilan perawat dalam melakukan asuhan keperawatan dapat dilihat dari kemampuan dan kompetensi perawat dalam memberikan asuhan. Kompetensi klinik perawat merupakan penilaian tertinggi dari pendidikan, interpretasi, dan pengalaman dari berbagai situasi klinik. Kompetensi klinik menjadi hal yang penting bagi orang tua karena ada ketakutan dan kekhawatiran orangtua tentang perawat yang mungkin akan menyakiti atau melukai anaknya (Gillespie, et al., 2012). Perawat yang tanggap dan responsif dalam mem- bantu orang tua serta cepat merespons terhadap pasien dan keluarganya juga diungkapkan oleh ibu.

Hasil penelitian ini juga menyebutkan bahwa secara umum para ibu merasa puas terhadap perawatan yang diberikan di ruang NICU terutama dalam memfasilitasi kedekatan orang tua dan bayinya. Menurut para ibu perawatan yang dilakukan di ruang NICU sudah baik, meskipun ada juga ibu yang mengatakan bahwa ada perawat yang memberikan asuhan tidak sesuai dengan harapan orang tua. Hal ini menunjukkan kepuasan orang tua terhadap caring yang dilakukan perawat.

\section{Kesimpulan}

Pengalaman orang tua menerima perilaku caring perawat dalam memfasilitasi bonding attachment bayi prematur tergambar dalam tujuh tema, yaitu proses peningkatan pengetahuan, mampu melakukan perawatan terhadap bayinya, respons ibu terhadap tindakan perawatan yang diberikan, termotivasi dalam melakukan perawatan bayi prematur, terpenuhinya kebutuhan selama perawatan, keterlibatan dalam asuhan keperawatan, dan kepuasan terhadap perawatan. Rekomendasi hasil penelitian ini adalah institusi perlu memfasilitasi perawat dalam menerapkan proses bonding attachment bayi prematur dengan orang tua terutama ibu. Hasil penelitian dijadikan bahan masukan dalam mempersiapkan lulusan untuk melatih sensitifitas kebutuhan orang tua terutama bayi prematur dan dapat digunakan dalam mengembangkan riset keperawatan terutama yang berkaitan dengan perilaku caring perawat dalam memfasilitasi bonding attachment terhadap bayi premature (NN, INR, AM).

\section{Referensi}

Alligood, M.R. (2010). Nursing theory: Utilization and application (4th Ed.). Philadelphia: Mosby Elsevier.

Bowden, V.R., Dickey, S.B., \& Greenberg, C.S. (1998). Children and their families: The continuum of care. Philadelpia: W.B. Saunders Company. 
Boxwell, G. (2007). Neonatal intensive care nursing. New York: Routledge.

Cloherty, J.P., Eichenwald, E.C., \& Stark, A.R. (2008). Manual of neonatal care (6th Ed.). Philadelphia: Lippincotts Williams and Wilkins.

Cunningham, T.T., Carpenter, C.C., Charlip, R.B., Goodloe, J.L., Griffin, L.D., Maccione, N. Zuckerman, A.M. (2005). Patient satisfaction: Understanding and managing the experience of care. Second Edition. Chicago: Irwin Press.

Davis, L., Edwards, H., Mohay, H. \& Wollin, J. (2003). "The course of depression in mothers of premature infants in hospital and at home". Australian Journal of Advance Nursing, 21 (2), 20-26.

Gillespie, L.D., Robertson, M.C., Gillespie, W.J., Sherrington, C., Gates, S., Clemson, L.M., \& Lamb, S.E. (2012). Interventions for preventing falls in older people living in the community. Cochrane Database Syst Rev., 12 (9), CD007146. doi: 10.1002/14651858. CD007146.pub3.

Guillaume, S., Natacha, M., Amrani, E., Benier, B., Durrmeyer, X., Lescure, S., Ceymaex, L. (2013). Parent's expectations of staff in the early bonding process with their premature babies in the intensive care setting: A qualitative multicenter study with 60 parents. BMC Pediatrics, 13 (18), 1-9.

Harbaugh, B.L., Tomlinson, P.S., \& Kirschbaum, M. (2004). Parents' perceptions of nurses' caregiving behaviors in the pediatric intensive care unit. Issues Comprehensive Pediatric Nursing, 27 (3), 163-178. doi: 10.1080/0146 0860490497985 .

Juretschke, L.J. (2007). Do parents of premature infants perceive neonatal nurse practitioners as Caring? (Unpublished doctoral dissertation). Loyola University Chicago.
Proquest database.

Lopez, G.L., Anderson, K.H., \& Feutchinger, J. (2012). Transition of premature infants from hospital to home life. Neonatal Network, 31 (4), 207-214.

Merighi, M.A.B., Pinto de Jesus, M.C., Santin, K.R., \& Moura de Oliveira, D. (2011). Caring for newborn in the presence of their parents: The experience of nurses in the neonatal intensive care unit. Rev. Latino-Am Enfermagem, 19 (6), 1398-1404.

Potts, N.L., \& Mandleco, B.L. (2012). Pediatric nursing: Caring for children and their families (3rd Ed.). New York: Delmar Cengage Learning.

Swanson, K.M. (1995). Response to "The power of human caring: Early recognition of patient problem". Scholarly Inquiry for Nursing Practice: An International Journal, 9 (4), 319-321.

Watson, J., \& Foster, R. (2003). "The attending nurse caring model: Integrating theory, evidence and advanced caring-healing therapeutics for transforming professional practice". Journal of Clinical Nursing, 12, 360-365.

White, L., Duncan, G., \& Baumle, W. (2011). Foundations of maternal and pediatric nursing (3rd Ed.). New York: Delmar Cengage Learning.

Wilkin, K., \& Slevin, E. (2004). The meaning of caring to nurses: An investigation into the nature of caring work in an intensive care unit. Journal of Clinical Nursing, 13 (1), 5059. Doi: 10.1111/j.1365-2702.2004.00814.x.

Willinger, U., Diendorfer-Radner, G., Wilnauer, R., Jorgl, G., \& Hager, V. (2005). Parenting stress and parental bonding. Behavioral Medicine, 31 (2), 63-80. 